\title{
A OPAS da Educação: a participação da Organização Pan-americana da Saúde na constituição do campo de recursos humanos no Brasil
}

CASTRO, Janete Lima de.

Protagonismo silencioso: a presença da OPAS na formação de Recursos Humanos em saúde no Brasil. Natal-RN: Observatório RH-Nesc/UFRN; MS/Brasil; OPAS/OMS, 2008. 267 p.

\section{| Carlos Henrique Assunção Paiva |}

Historiador, doutor em Saúde Coletiva, pesquisador no Observatório História e Saúde da Fiocruz. Endereço eletrônico: cpaiva@coc.fiocruz.br

O livro de Janete Castro trata da experiência de cooperação entre um organismo internacional especializado em saúde, a Organização Pan-americana da Saúde (OPAS/OMS) e o governo brasileiro, no período que se inicia em 1975 e segue até o final dos anos 1990, no que tange às políticas de formação de pessoal de saúde. Este período tem como marcos a criação do Programa de Preparação Estratégica de Pessoal de Saúde (PPREPS), de 1975; o movimento pela redemocratização política do país e fundação de um sistema universal de saúde em território nacional; e as experiências mais recentes na área de organização do sistema de saúde brasileiro, em especial aquelas relativas ao campo de recursos humanos.

Trata-se de um estudo ambicioso, tendo em vista não só as especificidades das experiências desenvolvidas naquele contexto, mas também a peculiaridade que envolve a inserção do debate sobre educação e gestão do trabalho no campo da saúde. A autora desenvolve esse estudo muito bem amparada em fontes, sobretudo depoimentos orais, provenientes dos mais diversos atores sociais, muitos dos quais figuras-chave para o desenvolvimento das experiências narradas em seu livro. Ela própria, diga-se de passagem, é uma dessas figuras de relevância, uma vez que constitui sua trajetória não apenas como pesquisadora, mas também como condutora de alguns dos planos e projetos da área em questão.

Com a finalidade de compreender o papel da representação brasileira da OPAS no campo de recursos humanos, Castro passa em revista experiências emblemáticas 
para a configuração desta área como um campo de produção de conhecimento e de gestão e políticas, como as do PPREPS, do Projeto de Formação em Larga Escala de Pessoal de Nível Médio e Elementar para os serviços de Saúde (Larga Escala), do Projeto de Capacitação em Desenvolvimento de Recursos Humanos de Saúde (CADRHU), e do Projeto de Desenvolvimento Gerencial de Unidades Básicas do Sistema Único de Saúde (GERUS), que são especialmente focadas.

No primeiro capítulo de análise do livro, "Intelectuais e ação política: a OPAS e o movimento da reforma sanitária brasileira”, a autora procura construir o papel da OPAS como difusora do pensamento da medicina social no Brasil, sobretudo em sua vertente acadêmica (ESCOREL, 1998), e suas conexōes com o chamado Movimento pela Reforma Sanitária Brasileira. Várias instituições e personalidades foram destacadas. Num primeiro momento, merecem ênfase o setor saúde do Centro Nacional de Recursos Humanos do Instituto de Pesquisa Econômica e Aplicada (CNRH/IPEA), a Financiadora de Estudos e Projetos (FINEP), o Instituto de Medicina Social da UERJ, entre outras; em seguida, merecem destaque os trabalhos de Cecília Donnangelo, de Sérgio Arouca e, principalmente, de Juan César Garcia. A trajetória deste último, nos diz Castro, se confundiria com o próprio desenvolvimento da medicina social latino-americana. Outro aspecto da trajetória de Garcia, digna de maior investigação, diz respeito a sua capacidade de realização numa instituição que não necessariamente se encontrava aberta ou completamente permeável às suas propostas. Ao contrário, Garcia não deixou de enfrentar a resistência de projetos e áreas mais prestigiosas dentro da Organização.

$\mathrm{Na}$ verdade, segundo a autora, em diferentes posiçōes, personagens como Juan César Garcia, Sergio Arouca, Hésio Cordeiro, José Paranaguá de Santana, Roberto Passos, entre outros, foram capazes de construir e constantemente reconstruir um "sistema de vasos comunicantes", que deu liga às propostas, projetos e trajetórias, num esquema de solidariedade que permitiu que, com apoio pessoal e institucional mútuo, propostas não-hegemônicas ganhassem visibilidade pública e apoio oficial. Assim, já ao primeiro capítulo do livro, Castro nos apresenta umas das conclusōes mais interessantes de seu trabalho: o verdadeiro movimento de mão-dupla que havia entre as equipes técnicas da OPAS e o movimento pela reforma sanitária brasileira. Numa trajetória de retroalimentação, tanto um, quanto o outro, se influenciaram mutuamente, de forma que não é possível perceber, no caso brasileiro, uma experiência nacional que seja decorrência linear de uma proposição da OPAS. 
No capítulo 2, "A arquitetura do programa de recursos humanos da OPAS no Brasil”, a autora constrói o processo de implantação e consolidação do Programa de Cooperação em Desenvolvimento de Recursos Humanos da OPAS/ Representação Brasil. Seus marcos, por sua vez, se situam no contexto de implantação do PPREPS em meados dos anos 70. A partir da experiência de trabalho do PPREPS, experiências como o Larga Escala, o CADRHU e o GERUS se desenvolveram ao longo da década seguinte (PIRES-ALVES; PAIVA, 2006). Inclusive, como chama bem a atenção o trabalho de Castro, o PPREPS desempenhou importante papel indutor na implantação do "sistema de vasos comunicantes" acima comentado (CASTRO, 2008, p. 111).

Nesta seção do trabalho, ainda que muito ligeiramente, Castro não deixa de apontar para o rico debate doutrinário que movimentou atores de diferentes "escolas sanitárias brasileiras". Neste contexto, os chamados campanhistas, sespianos (estes formados pelo Serviço Especial de Saúde Pública - SESP), e desenvolvimentistas disputavam prestígio e capacidade de influenciar as agendas de trabalho em saúde pública e de formação de pessoal para os serviços de saúde no país.

No capítulo 3, "A materialização da cooperação técnica", Castro dá ênfase às três experiências de formação de pessoal apresentadas no capítulo anterior: o Larga Escala, o CADRHU e o GERUS. Entendida, nos termos de Pires-Alves e Paiva (2006), como um segundo momento da cooperação técnica OPAS-Brasil, em que a agenda de trabalho da cooperação se amplia rumo a temas mais abrangentes, como para a organização do sistema de saúde, esta fase mostra bem a estreita relação que o papel da equipe técnica da OPAS teve, toda ela composta majoritariamente por brasileiros, para o arranjo da chamada reforma sanitária brasileira e a composição do Sistema Único de Saúde. No campo dos recursos humanos propriamente dito, Castro chama a atenção para a função emolduradora do projeto Larga Escala para as demais experiências nesta área e especialmente para o fato de uma organização especializada em saúde ter sido capaz de, em determinado contexto, produzir um ambiente normativo para os assuntos educacionais (ainda que voltados para o setor saúde). Assim, da necessidade de melhor conectar as necessidades dos serviços de saúde ao padrão de formação de pessoal para o setor, nasceu uma proposta que, nos termos de Paulo Freire (1987), se posicionava contra um padrão de educação denominado "bancário", buscava-se a problematização dos processos de trabalho em saúde, bem como a constituição 
de trabalhadores engajados eticamente, conscientes do seu papel para o desenvolvimento de um sistema de saúde que se pretendia universal e integral. Neste sentido, a autora conclui que:

o Projeto Larga Escala nasceu da necessidade de equacionar dois graves problemas com os quais se defrontavam os serviços de saúde e o sistema educacional: a inadequabilidade deste último, no sentido de integrar teoria e prática; e a incapacidade do primeiro, em promover programas de formação de pessoal, que fossem além das usuais propostas de treinamento, fragmentadas e pontuais. (p. 158).

Ao apoiar-se extensamente nos depoimentos daqueles que fizeram e fazem a cooperação técnica OPAS-Brasil em recursos humanos para a saúde, a autora - ela mesmo parte deste movimento - talvez tenha, em alguma medida, se descuidado de um necessário distanciamento para com narrativas de vida, construçôes e pontos de vistas pessoais acerca do passado, abdicando, assim, de uma postura mais rigorosa. Isto, contudo, longe de comprometer a qualidade do trabalho, o torna uma fonte relevante de informações, alimentando a reflexão sobre as políticas voltadas para aqueles que, a bem da verdade, materializam a constituição de um sistema público de saúde universal - os seus trabalhadores.

Nesse contexto, como bem nos mostra Castro, ainda que a OPAS seja uma instituição especializada nos assuntos da saúde, seu protagonismo silencioso foi também ingrediente fundamental para o desenvolvimento de políticas educacionais e mesmo para a configuração atual do campo de recursos humanos em saúde no Brasil.

\section{Referências}

ESCOREL, S. Reviravolta na saúde: origem e articulação do movimento sanitário. Rio de Janeiro: Fiocruz, 1998. $208 \mathrm{p}$.

FREIRE, Paulo. Pedagogia do oprimido. Rio de Janeiro: Paz e Terra, 1987. 218 p.

PIRES-ALVES, F.A.; PAIVA, C.H.A. Recursos criticos. História da cooperação técnica OPAS-Brasil em Recursos Humanos para a Saúde (1975-1988). Rio de Janeiro: Fiocruz, 2006. 203 p. 